\title{
2 Men Opting out: Disenchantment with Corporate Cultures and Career Ideals
}

\begin{abstract}
Opting out of successful careers has been a highly debated topic ever since New York Times columnist Lisa Belkin published her article 'The Opt-Out Revolution'. However, men have not been included in the debate, nor has it captured contemporary, societal aspects, as it has focused solely on women who leave to care full-time for children. I have thus broadened the definition of opting out to include opting in to new lifestyles or solutions for work. Mainstream career models no longer accurately describe preferred or actual career patterns and progressions. In addition, although prevalent career models are based on masculinist norms, they do not leave much room for diversity among men. Using a narrative approach, this chapter draws on the narratives of 29 men from Finland, the UK and the US who opted out of mainstream masculinist careers to pursue new lifestyles and solutions for work. The men typically felt disenchanted with corporate ideals and expectations as they progressed up the career ladder. This disenchantment came from internal struggles associated with increased pressure and stress on the one hand, and ethical issues regarding the treatment of, for example, employees and clients on the other. Opting out allowed them to create solutions for work that provided a sense of coherence, authenticity and wellbeing, and made it possible for them to spend time and nurture the relationships with people who were important to them.
\end{abstract}

\section{Introduction}

Opting out has been a debated topic ever since New York Times columnist Lisa Belkin (2003) coined the term “opt-out revolution” in 2003 (Jones 2012; Williams et al. 2006). However, as the debate has focused on questions of gender and women who leave their careers altogether to become stay-at-home mothers, it has missed important societal perspectives, like the effect of contemporary working cultures on individuals' identities and sense of self. Nor has it recognised that opting out may not only be a women's issue, even though it has been argued that the opting out debate should also include men (Zimmerman and Clark 2016; McKie, Biese and Jyrkinen 2013; Aumann and Galinsky 2012).

In her column, Belkin (2003) wrote about high-powered women who did not feel that their successful careers had provided them with a successful life. They raised issues like balance and sanity to describe what they had been missing in 
their previous careers and what they were looking for in their new lifestyles. Reactions to the column have been mixed, however much of the research on opting out is critical, arguing that this so-called revolution is a myth, because if women are leaving their careers, they are being pushed out of masculinist cultures instead of leaving by choice (see Cossman 2009; Boushey 2005; Percheski 2008; Stone 2007). Critics have shown that there is, in fact, no statistical evidence that career women are leaving successful careers in any great or rising numbers; highly educated women rarely stop working altogether to stay at home full-time with their children (Zimmerman and Clark 2016; Boushey 2005, 2008; Percheski 2008). However, the statistics have not captured individuals who leave successful careers but stay in the labour market and work on different terms, as they have merely focused on those who stop working altogether.

As I will illustrate in this chapter, opting out is not only about women, nor is it only about individuals who juggle work with childcare. I have thus broadened the definition of opting out to include opting in to alternative lifestyles and solutions for work. This definition is not bound to any one gender and it encompasses contemporary work cultures, which are continuously becoming increasingly hectic. The globalised digital economy has contributed to creating a culture where individuals struggle to adjust to new experiences of the self (Elliott 2013). Long-term focus has been replaced by short-termism and quick wins, and individual flexibility and adaptability are crucial in order to survive the ever-tougher corporate climate and workplace conditions (Sennett 2006). As the focus has shifted from knowledge and experience to having potential and an ability to adjust to change and survive in a flexible, ambiguous environment, individuals are typically left with feelings of insecurity and ambiguity, making it difficult for them to create coherent narratives of their life and work (Elliott and Lemert 2006).

According to the Kelly Global Workforce Index 2014, approximately half of all global workers are unhappy in their jobs, mainly due to a lack of security caused by constant cost-cutting and restructuring. Middle managers have been found to be among the unhappiest (Zenger and Folkman 2014). The American Psychological Association (2015) reports work and money as the two top sources of stress and in the past decades, work-related stress has had a substantial adverse effect on health (Ganster and Rosen 2013; Cottini and Lucifora 2013; Pfeffer 2018). In the Nordic countries, for example, the cost of care for mental illness has skyrocketed since 1991 and is today by far the largest healthcare cost (Ahonen et al. 2016). Nevertheless, when it comes to health issues, the focus is on the individual and the individual's lifestyle choices instead of focusing on the structures in society that are the sources of these increasing health issues and costs. 
It is against this backdrop that opting out needs to be explored not only as a phenomenon where highly educated women leave the workforce altogether, but where both men and women leave a certain work ideal and career model to create alternative ways of working. In 1993, a decade before Belkin wrote her column, Barrentine (1993) argued that when corporate environments become toxic, women are the first to leave, but that men will soon follow. More recently Mainiero and Sullivan (2006) have also argued that opting out is indeed something that we will see more of.

In this chapter, I introduce men to the opting out debate. I have interviewed professional men from Finland, the United States (US) and the United Kingdom (UK), who opted out of successful careers to adopt alternative lifestyles and solutions for work. I will explore the reasons why they opted out and how they make sense of their experiences. I will start with a discussion of prevalent masculinist career ideals, corporate environments and changing masculinities in contemporary society. Next, I will introduce my research project, my methodology and the data set that I draw on in this chapter. I will also briefly describe the central themes in my earlier research on women opting out and explore how these have informed my current research on men opting out and how they compare to the men's narratives that I have collected. After that, the narratives will be introduced and analysed, looking specifically at what it was about the corporate environments that made the men decide to leave. Although all the men also opted in to new lifestyles and solutions for work, the focus in this chapter is on the opting out part of the men's processes, and the reasons behind their decisions to leave. I have distinguished three main themes: 'exhausted and disillusioned', 'unethical treatment of others' and 'difficulties coping with the pressure', according to which the analysis is structured. Finally, I will end with a discussion and thoughts for further research.

\section{Masculinist Career Ideals and Changing Masculinities}

The roots of the contemporary masculinist linear career model date back to the dawn of industrialisation, and the notion of a career gained a foothold as a result of the prosperity many nations experienced after World War II (Greenhaus et al. 2010). The employee was expected to be devoted to the job and could advance upwards in the organisational hierarchy through promotions. As middle-class families shifted from being a producing to a consuming unit, a dualism of public versus private spheres was created. Women were generally assigned to the private 
realm of the home, while the public sphere of paid work and politics was mainly considered a man's world. However, as men could move between the two spheres, access to these was highly gendered (see for example Kinser 2010). Working in the industries took employees away from the home, and someone needed to stay to take care of the children and the household. It has thus been argued that the masculinist linear career model was planned for not one but one and a half people: the man with a career, and his wife who took care of all the things that the man no longer had time for (Beck and Beck-Gernsheim 2002).

The masculinist linear career model no longer necessarily corresponds to contemporary individuals' lifestyles, preferences and needs, particularly as both men and women increasingly work and share care responsibilities and household chores (Greenhaus et al. 2010; McKie et al. 2013; Biese and Choroszewicz 2018). Careers today are multidirectional and boundaryless (Schreuder and Coetzee 2006; Mainiero and Sullivan 2006; Connell and Messerschmidt 2005). Nevertheless, the linear career ideal, which expects $24 / 7$ commitment and devotion, continues to be the norm especially for those who strive to reach the upper echelons of corporate hierarchies (Blair-Loy 2003; Biese and McKie 2015). Not only does this leave few alternatives for individuals who want or need to organise their work differently, ironically, prevalent masculinist career ideals do not leave much room for diversity among men either (Connell and Messerschmidt 2005).

Social masculine norms are situated in time and place and are subject to historical development and change (Connell and Messerschmidt 2005). During the past decades there has, for example, been a rise in caring masculinities and new fatherhood as a result of women's increased participation in the public sphere and initiatives to increase fathers' involvement in childcare (Borve and Bungum 2015). However, despite this, there continues to be evidence of normative patterns of practice and the idea of an "honored way of being a man" (Connell and Messerschmidt 2005, 832). Hegemonic masculinity has proven useful when studying the gendered nature of organisations (Connell and Messerschmidt 2005; Connell and Wood 2005) and the global corporate economy is argued to be the setting for a pattern of hegemonic masculinity that Connell (1998) has termed "transnational business masculinity". While hegemonic masculinities are in part bound by national cultural norms, global organisational cultures dominate and reinforce gender structuring and masculine ideals despite national differences (Collinson and Hearn 1996; Hearn and Piekkari 2005; Biese and Choroszewicz 2018) and managers have thus become an important group for understanding modern masculinities (Collinson and Hearn 1996). Organisational cultures have been found to override national difference and legislative support for professionals with, for example, care responsibilities (Hobson et al. 2011), making experiences 
among corporate executives similar despite different cultural contexts (Biese and Choroszewicz 2018; Biese 2017).

Personal success in the workplace in the form of salary and promotion has been found to be central to men's identity construction and sense of self (Collinson and Hearn 1994). Choosing to opt out of a career defined by objective success measures (see $\mathrm{Ng}$ et al. 2005) could thus potentially pose a threat to identity. In addition, while women increasingly work and participate in supporting the family financially, the breadwinner ideal still continues to have a strong foothold (Tinsley et al. 2015). Men are expected to support their families financially, even in a country like Finland, which is considered one of the most gender equal countries in the world, and where there is a tradition of women working (Jyrkinen and McKie 2012). Opting out is thus harder for men to do than it is for women (see also Pajumets and Hearn 2012).

\section{Men Opting Out}

This chapter draws on the data collected for a research project titled 'New meanings of work: Men opting out of mainstream career models to adopt alternative approaches to work', funded by the Academy of Finland. For the project, I interviewed 29 male professionals from Finland (15), the UK (5) and the US (9), ranging between the ages of 32 to 63, who had opted out of mainstream masculinist career models to work and/or live on different terms. The US was a natural place to start, as that is where the opting out debate originated. The UK and Finland serve as contrasts. Both countries have more family-friendly policies and practices, which make it easier for individuals to combine work with other responsibilities. London - where the UK men in my data set worked before opting out - is a financial centre in Europe with highly competitive work cultures and practices, while Finland is a welfare state and is considered one of the most gender equal countries in the EU. Finnish fathers, for example, have a legislative right to paternity leave and are encouraged to take an active part in childcare (Eurostat 2016).

In the interviews, I used a free association-narrative approach (see Hollway and Jefferson 2000). This approach was appropriate as the objective was to study not only reasons behind decisions to opt out and what the men chose to do instead, but also to explore questions of identity and how their decisions affected their sense of self (see for example Hoyer and Steyaert 2015). As questions of identity are not always conscious, this approach provides the deep insights needed to explore what lies behind individuals' choices (Hollway and Jefferson 2000). The interviews were conducted between 2015 to 2017, lasted 
between one and two and a half hours, and were recorded and manually transcribed. They were unstructured with few open-ended questions; the men were asked to speak freely about their experiences from the time before opting out to when they had opted in to their new lifestyles or ways of working. This allowed them to decide what they told and how. By not imposing structure on their narratives, they were able to elaborate as much as they wished without judgment or interpretation (Hollway and Jefferson 2000).

All the men in this study left mainstream masculinist careers models to live and work on different terms. Most of them worked in the private sector and held middle to upper management corporate positions before they opted out. They were thus on their way or already in the upper levels of corporate hierarchies. After they opted out, they opted in to a variety of different solutions for work. Some became entrepreneurs, some retrained and started working in another field, and some simply started working in organisations that allowed them to do so at a slower pace and on different terms. Although most of the men were fathers, five were not. Several of the men from the US, where high-quality day care is expensive and not readily available (Still 2006), became stay-at-home fathers, either for a period of time or indefinitely after opting out. This was not the case among the Finnish and UK men in my data set, of which only one became a stay-at-home father.

As I collected and analysed the men's narratives, I found that their opting out and in processes were quite similar to those of the women I had researched in an earlier study on opting out (see Biese 2017). Despite being from different countries, all the women I interviewed went through a similar process as they opted out and in. Before opting out, they experienced a lack of agency and control, and they found it difficult to created coherent narratives of their lives and work. Then a crisis made them realise they could no longer go on the way they had, which subsequently encouraged or pushed them to make a change. Although the issue of crisis had only been briefly mentioned in previous research (see for example Mainiero and Sullivan 2006), it was what the decisions to opt out and in hinged on for the women I interviewed (Biese 2017). After opting in to new lifestyles and solutions for work, they experienced a newfound sense of coherence, control, and authenticity, which, in turn, had a positive effect on their wellbeing (Biese 2017; Biese and McKie 2015; Biese and Choroszewicz 2018).

The same issues were also present in the men's narratives. Although they did not express it in these words, in most of the narratives, experiences of incoherence before opting out, a crisis, and the newfound sense of authenticity, coherence and control after opting in to their new lifestyles and solutions for work could be clearly discerned. The exception was a few of the stay-at-home fathers in the US, whose decisions to opt out were the result of discussions with their wives of how 
to organise their family care responsibilities and finances. However, while the processes were similar to those of the women, the details differed. Due to different societal gender norms and expectations, factors that caused the lack of coherence before opting out often differed. Women typically deal with the burden of being mainly responsible for care work in society (McKie and Callan 2012) and often struggle to juggle that with a career that craves complete dedication and constant availability (Blair-Loy 2003; Biese and Choroszewicz 2018). Men, on the other hand, are generally much freer to spend long days at work. Another difference is that women are often told they can do anything they want to and are encouraged to follow their hearts when choosing a profession (Slaughter 2012). In contrast, the men in my dataset were much more bound by expectations and prestige when choosing a profession or what to study at university. Some were pressured by family members to do what other men in their family had done, or to choose something that would provide them with good job prospects and a high status and salary so that they could provide for a future family. This invariably added to the lack of coherence they felt before opting out.

To understand what exactly caused the men in my dataset to opt out, I examined the different phases of their opting out and in processes, paying special attention to the crisis each typically went through. There were two common issues that were recurrent in most of the narratives. One was a realisation that their chosen profession was not 'right' for them, that they felt they had to be someone they were not at work before opting out. The other was disenchantment with the corporate cultures and ideals. I have further divided these issues into three subthemes: 'exhausted and disillusioned', 'unethical treatment of others' and 'difficulties coping with the pressure'. I have structured the data analysis according to these sub-themes and I have chosen quotes from my dataset, where these issues are especially clearly expressed and illustrated. As the interviews were conducted in three languages - English (the US and UK interviews), Finnish and Swedish (the Finnish interviews) - I have translated the quotes of the Finnish men. Pseudonyms have been used and identifying details have been changed to protect the men's anonymity.

\section{Disenchanted with Corporate Cultures and Career Ideals}

Of the men in my study, all but two were in middle or top management positions. The pressure and expectation of 24/7 commitment and availability was a reality to them, and it did not leave time for much else in their lives. All but five 
were fathers. Despite the rise of caring masculinities and new fatherhood (Borve and Bungum 2015), as well as legislation and initiatives that encourage men to take a more active role in the care of their children, there is relatively little support and understanding for this in organisations (Choroszewicz and Tremblay 2018; Biese and Choroszewicz 2018; Hobson et al. 2011). The jobs of all the men - both those who were fathers and those who were not - left little room to nurture relationships and pursue other areas of interest. However, this alone was not enough to push them to leave their careers. Many of the men also felt disenchanted by corporate cultures, practices and career ideals. In the narratives I collected, I discerned three recurring sub-themes related to the disenchantment the men in my dataset experienced. In the following I will present these three sub-themes, illustrating them with quotes from my dataset. I have chosen quotes from the narratives that especially clearly illustrate each subtheme. However, the men's experiences often overlap and because of that the quotes may simultaneously be examples of more than one of the themes.

\section{Exhausted and Disillusioned}

Matti in Finland was a management consultant when he opted out. He was 30 years old and physically and mentally exhausted by the time he handed in his letter of resignation. As a consultant he worked very long hours:

What we did at [the company] was completely crazy, we get better work done now [at the company I started working for after opting out] than we did there [where we worked very long hours] . . . I think the culture is the same in all consultancy companies. You look up to people who work a lot, look up to those who work the most hours and you work all night so that you are the king of the office and it's like wow. . . I have, for example, worked 28 hours in one go and it's like wow that's so cool and then afterwards you're like 'I'm an idiot.'

(Matti, 34, Finland)

Working extremely long hours was both encouraged and admired; and it was not until after he opted out that Matti realised how extreme the situation really was. He was on annual leave when he noticed how tired he was. Nevertheless, it was not just the exhaustion that pushed him to leave; it was also an incident at work that made him realise that he did not want to do it anymore. Before he went on holiday, he had been blamed for a mistake that he had not even been involved in. He felt wrongly accused and badly treated:

Consultants have exactly as much credibility as their numbers. If they are right, everything is okay but if they are wrong there is huge panic, so there was actually an incident, which didn't actually have anything to do with me, but I got the crap for it.

(Matti, 34, Finland) 
He was angry about getting the blame for someone else's mistake, and he just did not feel he could handle going back after his holiday. He wanted to do something completely different. He had been passionate about photography ever since he was a boy and had played with the idea of doing it professionally. The savings he had accumulated as a consultant got him started, but he had difficulties getting his photography business off the ground and he soon realised he needed to find another job that would provide him with an income. He eventually started working as a manager at a company with more humane hours. In other words, he went back to the world of business but on different terms.

As can be discerned in Matti's quote, it was not only the long hours that he experienced as extreme, it was also the corporate culture, which, in combination with the pace and the hours, became untenable.

This frustration with the corporate culture is also echoed in John's narrative. John is from the UK and was a director in a multinational organisation when he opted out. As he climbed the corporate ladder and got more administrative responsibilities, he no longer had time for design work, which he loved and was what had originally brought him to the organisation. He did not like the corporate politics that came with his managerial responsibilities and he became increasingly demotivated. After a long period of soul searching and thinking about what he should do, he finally resigned and got a job as a designer with no managerial or administrative responsibilities at another organisation. Taking what could be seen as a backwards step, he stepped off the career ladder and as a result felt happier than he had felt in a long time. He comments,

\footnotetext{
[O]rganisations that . . . don't understand common sense, that cannot adapt to common sense, really is frustrating. You've got people who get frustrated because it's not going the way they want so the toys fall out of the pram . . . rather than actually looking at what they need to achieve they worry about . . . each individual step of the process and cannot get the grasp of a bigger picture on certain things because it's all sort of about personal ego and looking the best all the time and . . . winning. It needs to be winning for the right reason if you see what I mean. Sometimes there's a lot more of 'me' winning than 'us' winning [. . .] The lack of common sense, the management by fear . . . it just wasn't where I wanted to be.

(John, 45, UK)
}

Just like in Matti's case, it was not only the long hours and the expectation of 24/ 7 availability that was difficult, it was also the organisational culture. John felt frustrated by the individualistic nature of work and what he thought of as childish and irrational behaviour on the part of some of his colleagues. He struggled to find meaning in his work, which he had not gotten from climbing the corporate ladder. On the contrary, it had taken him away from doing what he loved being a designer. He had been promoted to a top managerial position and the politics and administration that came with that made his work feel meaningless. 


\section{Unethical Treatment of Others}

For some of the men in my data set, the disenchantment was not about how they themselves had been treated or about the lack of meaning in their work, it was rather about witnessing how others were treated in or by their organisations. For Rick in the US, for example, it was witnessing how his wife had been discriminated against and sexually harassed in the industry where he worked. He was a lawyer and worked in a very male dominated industry. He claimed that he never really loved being a lawyer; rather than prompted by his feeling passionate about law, his decision to become a lawyer was based on his idea of it being a prestigious profession with the possibility of making good money. Rick opted out of his career as a lawyer to start teaching, and although he still works, his wife is now the main breadwinner in their family. His decision to leave was largely based on having witnessed how his wife had been badly treated:

[I]t was a very male oriented . . . industry [. . . ] she was the only woman there and they just drank and they drank until it was time to get the last train . . . and that was the first indication that they really didn't want to talk to my wife [. . .] she wasn't treated really as a peer, she wasn't treated as a lawyer so that was probably part of me seeing you know the end in a sense . . . I didn't know it then but this was like I wasn't ever going to fit in.

(Rick, 54, US)

When I interviewed Rick, he talked at length about his wife's experiences, and it was clear how disillusioned and disturbed he felt by what she had gone through. He mentioned a job interview she had been to where the male interviewer had acted very inappropriately towards her. He describes it as a defining moment when he knew that working as a lawyer simply was not for him:

[A]nd he goes . . . I can imagine you dancing on my desk with nothing but a rose in your mouth. [How] women are treated differently even though she has equal [or] better qualifications than I did, you know [it] became very apparent to me.

(Rick, 54, US)

Topi in Finland was also concerned with the treatment of others, although it was not specifically an issue of gender. He felt that the employees in his company - in one department in particular - were treated unethically. He was a senior manager before opting out and it was one of the main issues behind his decision to leave and retrain as a paramedic:

Their working space was quite inhuman, they were jammed into a very small space and I had been talking about it for a long time [about how] this is completely impossible. They had to call clients from there . . . and the acoustics . . . I had been saying for a long time that we have to find a solution, we have to find money in the budget . . . so they can 
physically have more space ... I got the feeling that sometimes you keep animals better than that; horses have more space in their stables.

(Topi, 48, Finland)

He had also noticed that employees were discriminated against because of their age and felt that the organisation took advantage of their situations:

[P]eople whose careers were at the point that they were of an age where they couldn't really change [jobs] anymore ... they wouldn't have found anything . . . I think that was one of the reasons they were treated the way they were and the young [employees] who were recruited on a temporary basis even though they should have gotten a fixed contract . . . Often they left and felt that neither they nor their work was valued by management, who at the same time got big bonuses.

(Topi, 48, Finland)

The final straw for Topi was when his superior wanted him to fire one of his subordinates on what he felt were unethical grounds. He just could not do it. Soon after, he handed in his letter of resignation.

\section{Difficulties Coping with the Pressure}

In addition to the disillusionment many of the men experienced, there was also an internal struggle to cope with the pressure that came with the job. This included pressures associated with performance and responsibility and thus went beyond the hectic pace and extreme hours described above. For Kasper in Finland, for example, the higher up he climbed on the career ladder, the more he realised he wasn't comfortable doing what was expected of him. He explained that when he graduated from high school, his decision regarding what to study was very much based on prestige, earning potential and what his friends were choosing to do. He did not spend a lot of time thinking about the type of person he was and what he really wanted. When he graduated, he started working for a management consulting firm and at first, he liked the job. He liked working on projects. However, the higher up in the corporate hierarchy he climbed, the more he had to focus on sales - on finding and recruiting new clients:

[It] started feeling like the work as such is fun but I don't really have the energy to do it on these terms . . . 150\% . . . and then as I came higher up on the career ladder . . . there was an expectation at every step . . . there was more focus on sales and correspondingly less focus on project work . . . With this last promotion . . . it became quite clear.

(Kasper, 42, Finland)

He defined himself as an introvert, and sales work was just not something he was comfortable doing. At the same time, he had issues with what was being offered to prospective clients. He felt uncomfortable if they were promised things 
that he did not think his organisation would actually be able to deliver. It came to a point when he felt compelled to withdraw an offer right before signing as he was convinced that his company would not be able to live up to their end of the deal. As a result, the company lost the client. It was not looked upon kindly and he was taken off the project, which was bad for his record and a shock to him. It was what kick-started his opting out and in process. He explains,

"There was another . . . sales case that I led and there was great pressure . . . like what can we promise . . . this is the dilemma in the consultancy world. You sell services that aren't always easy to define and sometimes you have to sell something, promise a certain result without really knowing how you will be able to do it. There was . . . very much uncertainty [. . .] and finally I backed out as I didn't really dare promise what they wanted . . . there was great pressure, mental pressure in the process . . . I felt I have to be mentally stronger to survive the pressure.

(Kasper, 42, Finland)

For Kasper the pressure and uncertainly simply became too much. Peter from Finland also had trouble coping with the pressure, although it was of a different nature from that which Kasper experienced. Unlike Kasper, he did not define himself as an introvert, but in the interview, he gave an impression of being quite shy and sensitive. His speech was hesitant from time to time, especially when recounting experiences that clearly were difficult for him to talk about. Peter started working as a trader right out of business school. He was successful and made large amounts of money for his clients, but the pressure and the risk of losing everything and being liable was more than he could handle:

The more responsibility I got, the more I noticed I felt sick in the mornings and I got easily stressed [. . . I I decided to do it . . . on a much smaller scale and by myself [in my own company] . . . I don't have to make loads and loads [of money], my goal is to have a moderate salary and more free time, be with my family and not have that stress so that I need to wake up in the morning and go by the bathroom and vomit, which I did for eight [years]. Every morning I felt sick. I didn't always vomit but I always felt sick in the mornings.

(Peter, 40, Finland)

After Peter opted out, he set up his own business and started working on a much smaller scale with substantially less risk. Although he misses the comradery, he does not regret his decision. He makes a moderate amount of money, nothing like he made before, but he and his family can live comfortably. He does not feel a need to make the kind of money he made before, or to be successful according to objective definitions of success (see $\mathrm{Ng}$ et al. 2005). It is not as important as his wellbeing, and he now feels both safer and happier. He keeps in touch with his former colleagues, and they have, on several occasions, asked him if he wants to come back, but his answer is always 'no'.

Tom in the UK also worked at an investment bank when he opted out. Like Peter, he came to a point when the pressure became too much to handle. 
However, unlike Peter, Max was not a trader; he had a top managerial position in the organisational hierarchy. His career had gone from strength to strength; outwardly everything seemed to be going well. However, he had been dreaming about doing something else for years. He and his wife had talked about it, but he had never acted on that dream:

We've had conversations over the years ... I was really close about 10 years ago to train
to be a therapist so this interest in people and this sort of desire to help . . . had been
lingering around for a while ... and she'd often go if you want to do it just do it . . and
then no no yeah yeah it got better at work . .
(Tom, 43, UK)

The threshold to make a major change like opting out is very high as it entails leaving the known for the unknown. It was not until the company went through a process of change that was especially stressful, that he finally decided that he needed to do something about his situation. He had seen what stress could to someone and he realised that it just was not worth it:

The push factor was getting out of that environment and part of me just wanted to run away from the whole thing [. . .] I'm not enjoying my job and I can't do it anymore, I really cannot do it and I don't want to turn out like my brother [who had a breakdown due to work exhaustion].

(Tom, 43, UK)

When he finally did opt out, he started retraining as a nutritionist and has since set up his own business. Although it has not been an easy transition and he struggles to get his company on its feet, his new lifestyle provides him with meaning. He feels like he is finally where he is meant to be. He comments: "So I know now what my purpose in life is, why I'm on this planet” (Tom, 43, UK).

This is common among individuals who have opted out and in (Biese 2017). On the one hand, the feeling of authenticity is the result of the soul searching, the crisis and the opting out process, but it is also a result of the coherence and sense of authenticity that comes from creating solutions for work where they feel they have more control over their work and lives (Biese and McKie 2015). As a result of the opting out debate focusing only on women who leave to become stay-at-home mothers, one misconception many have about opting out is that when individuals opt out they leave the workforce altogether. Most of the individuals I have interviewed - both men and women - could not afford to stop working altogether, nor did they want to. The amount of work was not necessarily the main issue either. The issue was rather a feeling of not having control over their lives and their time. They lacked the ability to control where, when and how they worked and where, when and how they spent time with family or focused on other aspects of their lives that were important to them (Biese 2017; Biese and Choroszewicz 2018). 
In his interview, Kasper eloquently sums this up:

I think the amount of work is secondary. The primary factors are the conditions under which you work, the relationships to others, and what is expected of you and how it is communicated. Is one constantly under threat, does one constantly have the feeling that one can't handle it?

(Kasper, 42, Finland)

\section{Discussion and Conclusion}

The men in my study opted out of mainstream ways of doing careers to live and work on different terms. With the exception of two of the US men who became stay-at-home fathers without plans to re-enter the workforce in the future, the men adopted new ways of working which allowed them to work on their own terms and create their own definitions of what it means to be successful. For those with children, this included being able to be more involved in their lives, and many of those who did not have children also spoke of people and relationships, which their new lifestyles gave them more time to nurture. Working according to mainstream, masculinist norms left them little time for anything other than work. For many, the extreme stress and pressure became a lot to handle, and almost all of them felt disenchanted with the culture and practices of the organisational world they decided to opt out of. As mentioned previously, the exception was two of the men in the US who became stay-at-home fathers after making a joint decision with their wives.

The disenchantment the men experienced was on two different levels. For some it was internal and had to do with difficulties coping with the pressure or lacking a sense of purpose and struggling to find meaning. For others, there was an ethical aspect where they were concerned with the treatment of others, be it employees, clients or women. The crisis they experienced pushed them to opt out, but the disenchantment they felt towards the corporate world was central in shaping their decisions regarding what they subsequently chose to opt in to instead.

A feeling of authenticity and of finally doing what they felt they were meant to do was a recurring theme in the narratives. However, the reasons behind this feeling of authenticity are complex and multifaceted. It came from achieving a sense of coherence and control, but it may also, in part, be a coping mechanism to deal with the threat to identity and masculinity, which they potentially experienced as they gave up the things that are associated with objective measures of success, like a high salary and a prestigious job title (see $\mathrm{Ng}$ et al. 2005). For most of the men, opting out meant making less money, which, 
in turn, meant not being able to support their family or a potential future family the way they had been or would be expected to. During the interviews, this was clearly an issue and some talked about having to consider going back or rethinking their decisions due to financial reasons. This was often also the case for those who had wives with careers of their own and made more than enough money to support the family, which is illustrative of the strong foothold the breadwinner ideal still has.

The 29 interviews in my study are not enough to make any generalisations regarding men and the opting out phenomenon. However, what they do demonstrate is that men also do opt out and thus need to be included in the opting out debate, and that masculinist career models and ideals do indeed not suit all men. They provide an example of how contemporary working cultures and ideals can affect men and what this can lead to. More research needs to be done to find out how common opting out is and to understand what the long-term consequences may be. If opting out becomes more widespread in the future as some have predicted (see Mainiero and Sullivan 2006), it may potentially have an impact on organisations. More research could provide crucial information for organisations in the future, regarding how to broaden the notion of career to allow for a diversity of career paths that better suit individual wants and needs and how to change their practices in order to create sustainable work environments that will not only attract but also retain employees.

\section{References}

Ahonen, Guy, Tiina Pensola, Malin Lohela-Karlsson, and Steinar Aannaess. 2016. The cost of illness of the working-age population in the Nordic countries in 2012 - a comparison to 1991. Helsinki: Finnish Institute of Occupational Health.

American Psychological Association. 2015. "Stress in America: Paying with Our Health." Accessed December 20, 2018, https://www.apa.org/news/press/releases/stress/2014/ stress-report.pdf.

Aumann, Kerstin, and Ellen Galinsky. 2012. "The Real “Opt-Out Revolution” and a New Model of Flexible Careers." In Women Who Opt Out: The Debate over Working Mothers and WorkFamly Balance, edited by Bernie D. Jones, 57-84. New York: New York University Press.

Barrentine, Pat. 1993. "Introduction: Women as Harbingers of Business Transformation." In When the Canary Stops Singing: Women's Perspective on Transforming Business, edited by Pat Barrentine, 9-21. San Francisco: Berrett-Koehler Publishers.

Beck, Ulrich and Elisabeth Beck-Gernsheim. 2002. Individualization. London: Sage. Belkin, Lisa. 2003. “The Opt-Out Revolution.” The New York Times Sunday Magazine. October, 26. Biese, Ingrid. 2017. Opting out and in: On women's careers and new lifestyles. London: Routledge. 
Biese, Ingrid, and Marta Choroszewicz. 2018. "Creating Alternative Solutions for Work: Experiences of Women Managers and Lawyers in Poland and the USA." In The "New Normal' of Working Lives: Critical Studies in Contemporary Work and Employment, edited by Stephanie Taylor and Susan Luckman, 309-325. London: Palgrave Macmillan.

Biese, Ingrid, and Linda McKie. 2015. "Opting out and opting in: Women managers in search of balance, control and wellbeing." In Handbook on Well-Being of Working Women, edited by Mary L. Connerley Mary L. and Jiyun Wu, 503-516. London: Springer.

Blair-Loy, Mary. 2003. Competing Devotions: Career and Family among Women Executives. Cambridge: Harvard University Press.

Borve, Hege E., and Brita Bungum. 2015. "Norwegian Working Fathers in Global Working Life." Gender, Work and Organization 22(4): 309-323.

Boushey, Heather. 2005. "Are Women Opting Out? Debunking the Myth.” Center for Economic and Policy Research, Briefing Paper.

Boushey, Heather. 2008. “'Opting Out?' The Effect of Children on Women's Employment in the United States.” Feminist Economics 14(1): 1-36.

Choroszewicz, Marta, and Diane-Gabrielle Tremblay. 2018. "Parental leave policy by male lawyers in Helsinki and Montreal: Professional and cultural barriers to male lawyers' use of paternity and parental leaves." International Journal of the Legal Profession 25(3): 303-316.

Collinson, David L., and Jeff Hearn. 1994. "Naming Men as Men: Implications for Work, Organization and Management." Gender, Work \& Organization 1(1): 2-22.

Collinson, David L., and Jeff Hearn. 1996. "Breaking the Silence: On Men, Masculinities and Management." In Men as Managers, Managers as Men, edited by David Collinson and Jeff Hearn, 1-24. London: Sage.

Connell, Raewyn. 1998. "Masculinities and Globalization.” Men and Masculinities 1(1): 3-23.

Connell, Raewyn, and James W. Messerschmidt. 2005. "Hegemonic Masculinity: Rethinking the Concept." Gender \& Society 19(6): 829-859.

Connell, Raewyn, and Julian Wood. 2005. "Globalization and Business Masculinities." Men and Masculinities 7(4): 347-364.

Cossman, Brenda. 2009. "The 'opt-out revolution' and the Changing Narratives of Motherhood: Self-governing the Work/Family Conflict.” Utah Law Review 2: 455-474.

Cottini, Elena, and Claudio Lucifora. 2013. "Mental Health and Working Conditions in Europe." Industrial and Labor Relations Review 66(4): 958-988.

Elliott, Anthony. 2013. Reinvention. London: Routledge.

Elliott, Anthony and Charles Lemert. 2006. The New Individualism- the Emotional Costs of Globalization. London: Routledge.

Eurostat. 2016. “Gender statistics.” Eurostat Statistics Explained. (2016) accessed June 18 http:// ec.europa.eu/eurostat/statistics-explained/index.php/Gender_statistics\#Labour_market.

Ganster, Daniel C., and Christopher C. Rosen. 2013. "Work Stress and Employee Health: A Multidisciplinary Review." Journal of Management 39(5): 1085-1122.

Greenhaus, Jeffrey H., Gerard A. Callanan, and Veronica M. Godshalk. 2010. Career Management, 4th edition. Thousand Oaks: Sage.

Hearn, Jeff, and Rebecca Piekkari. 2005. "Gendered Leaderships and Leaderships on Gender Policy: National Context, Corporate Structures, and Chief Human Resource Managers in Transnational Corporations." Leadership 1(4): 429-454.

Hobson, Barbara, Susanne Fahlén, and Judit Takács. 2011. "Agency and Capabilities to Achieve a Work-Life Balance: A Comparison of Sweden and Hungary.” Social Politics 18(2): 168-198. 
Hollway, Wendy, and Tony Jefferson. 2000. Doing Qualitative Research Differently: Free Association, Narrative and the Interview Method. London: Sage.

Hoyer, Patrizia, and Chris Steyaert. 2015. "Narrative identity construction in times of career change: Taking note of unconscious desires." Human Relations 68(12): 1837-1863.

Jones, Bernie D. 2012. "Introduction: Women, Work, and Motherhood in American History." In Women Who Opt Out: The Debate over Working Mothers and Work-Family Balance, edited by Bernie D. Jones, 3-30. New York: New York University Press.

Jyrkinen, Marjut, and Linda McKie. 2012. "Gender, age and ageism: experiences of women managers in Finland and Scotland." Work, employment and society 26: 61-77.

Kelly Global Workforce Index. 2014. "A World at Work: Workers Across the Globe Talk Trends, Attitudes and Workplace Performance.” Accessed September 27, 2015, http://www.kellyservices.us/uploadedFiles/7-KellyOCG/2-Knowledge/Workforce_ Trends/A_World_At_Work.pdf.

Kinser, Amber E. 2010. Motherhood and Feminism. Berkeley: Seal Press.

Mainiero, Lisa A., and Sherry E. Sullivan. 2006. The Opt-Out Revolt: Why People are Leaving Companies to Create Kaleidoscope Careers. Mountain View: Davies Black Publishing.

McKie, Linda, Ingrid Biese, and Marjut Jyrkinen. 2013. “'The Best Time is Now!': The Temporal and Spatial Dynamics of Women Opting in to Self-employment." Gender, Work and Organization 20(2): 184-196.

McKie, Linda, and Samantha Callan. 2012. Understanding Families: A Global Introduction. London: Sage.

Ng, Thomas W.H., Lillian T. Eby, Kelly L. Sorensen, and Daniel C. Feldman. 2005. "Predictors of Objective and Subjective Career Success: A Meta-Analysis." Personnel Psychology 58: 367-408.

Pajumets, Marion, and Jeff Hearn. 2012. "Post- Socialist Fathers "at Home" and "Away from Home" in "Old Europe": Facing the Challenge Through Masculine Identity Talk." Studies of Transition States and Societies 4(1): 31-47.

Percheski, Christine. 2008. "Opting Out? Cohort Differences in Professional Women's Employment Rates from 1960 to 2005.” American Sociological Review 73(3): 497-517.

Pfeffer, Jeffrey. 2018. Dying for a Paycheck: How Modern Management Harms Employee Health and Company Performance - and What We Can Do About It. New York: Harper Collins Publishers.

Schreuder, Dries, and Melinde Coetzee. 2006. Careers: An Organisational Perspective, 3rd edition. Lansdowne: Juta \& Co. Ltd.

Sennett, Richard. 2006. The Culture of the New Capitalism. New Haven: Yale University Press.

Slaughter, Anne-Marie. 2012. “Why Women Still Can’t Have It All.” The Atlantic, July/August. Accessed December 20, 2018. http://www.theatlantic.com/magazine/archive/2012/07/ why-women-still-cant-have-it-all/309020/.

Still, Mary C. 2006. "The Opt-Out Revolution in the United States: Implications for Modern Organizations.” Managerial and Decision Economics 27(2-3): 159-171.

Stone, Pamela. 2007. Opting Out? Why Women Really Quit Their Careers and Head Home. Berkley and Los Angeles: University of California Press.

Tinsley, Catherine H., Taeya M. Howell, and Emily T. Amantullah. 2015. "Who Should Bring Home the Bacon? How Deterministic Views of Gender Constrain Wage Preferences." Organizational Behavior and Human Decision Processes 126: 37-48. 
Williams, Joan C., Jessica Manvell, and Stephanie Bornstein. 2006. “'Opt-Out’ or Pushed Out?: How the Press Covers Work/Family Conflict'.” WorkLifeLaw Report. San Francisco: UC Hastings College of the Law.

Zenger, Jack, and Joseph Folkman. 2014. "Why Middle Managers Are So Unhappy." Harvard Business Review, November 25. Accessed December 20, 2018. https://hbr.org/2014/11/ why-middle-managers-are-so-unhappy.

Zimmerman, Lauren M., and Malissa A. Clark. 2016. "Opting-out and opting-in: a review and agenda for future research." Career Development International 21: 603-606. 